\title{
Manejo de lepidópteros-praga na cultura do milho com o evento Bt piramidado Cry1A.105 e Cry2Ab2
}

\author{
José Magid Waquil(1), Patrick Marques Dourado(2), Renato Assis de Carvalho(2), Wladecir Salles Oliveira(2), \\ Geraldo Ubirajara Berger ${ }^{(2)}$, Graham Philip Head ${ }^{(3)}$ e Samuel Martinelli(3)
}

\begin{abstract}
(1)Rua Jovelino Lanza, № 210, Jardim Arizona, CEP 35700-353 Sete Lagoas, MG, Brasil. E-mail: jmwaquil@gmail.com (2)Monsanto do Brasil Ltda., Avenida Das Nações Unidas, oo 12.901, CEP 04578-910 São Paulo, SP, Brasil. E-mail: patrick.m.dourado@monsanto.com, renato.a.carvalho@monsanto.com, wladecir.s.oliveira@monsanto.com, geraldo.u.berger@monsanto.com ${ }^{(3)}$ Monsanto Company, 800 North Lindbergh Blvd., 63167 Saint Louis, MO, EUA. E-mail: graham.p.head@monsanto.com, samuel.martinelli@monsanto.com
\end{abstract}

Resumo - O objetivo deste trabalho foi avaliar a eficácia do evento piramidado (MON 89034), que expressa as proteínas Cry1A.105 e Cry2Ab2, no controle dos principais lepidópteros-praga da cultura do milho no Brasil, Spodoptera frugiperda, Helicoverpa spp. e Diatraea saccharalis. Os ensaios foram conduzidos em quatro regiões do país, com o híbrido DKB 390, submetido a seis tratamentos: híbrido com o evento piramidado, híbrido com o evento que expressa apenas a proteína Cry1A(b) (MON 810) e híbrido convencional (não Bt), todos com e sem manejo integrado de $S$. frugiperda. Para o evento piramidado, não foi necessário o controle químico em nenhum dos locais avaliados. Diferenças significativas foram observadas entre os tratamentos quanto aos danos e à presença de lagartas. Em geral, essas variáveis foram mais baixas no híbrido com o evento piramidado e mais altas no híbrido convencional, sem controle químico. Sob alta infestação, o controle químico reduziu os danos causados por $S$. frugiperda e $D$. saccharalis, tanto no evento que expressa apenas uma proteína, como no híbrido convencional. Com base nos danos causados pelos insetos, o evento piramidado Cry1A.105 e Cry2Ab2 é eficiente no controle dos principais lepidópteros-pragas do milho no Brasil.

Termos para indexação: Helicoverpa, Zea mays, broca, lagarta-da-espiga, lagarta-do-cartucho, manejo integrado.

\section{Management of Lepidopteran pests in maize crop using the $\mathrm{Bt}$ pyramided event Cry1A.105 and Cry2Ab2}

\begin{abstract}
The objective of this work was to evaluate the efficacy of the pyramided event (MON 89034), expressing Cry1A.105 and Cry2Ab2 proteins, in the control of the main lepidopteran maize pests in Brazil, Spodoptera frugiperda, Helicoverpa spp., and Diatraea saccharalis. The trials were conducted in four regions of the country, using the hybrid DKB 390, subjected to six treatments: hybrid containing the pyramided event, hybrid expressing only the protein Cry1A(b) (MON 810), and conventional hybrid (non Bt), all with and without integrated management for S. frugiperda. For the pyramided event, chemical control was not necessary in any of the evaluated locations. Significant differences were observed between treatments for larval damage and presence. In general, those variables were lower for the pyramided hybrid and higher for the conventional hybrid without chemical control. Under high infestation, chemical control reduced the damage caused by $S$. frugiperda and $D$. saccharalis both on the single protein event and on the conventional hybrid. Based on the damage caused by the insects, the pyramided event Cry1A.105 and Cry2Ab2 is efficient in the control of the main lepidopteran maize pests in Brazil.
\end{abstract}

Index terms: Helicoverpa, Zea mays, borer, corn earworm, fall armyworm, integrated management.

\section{Introdução}

A lagarta-do-cartucho, Spodoptera frugiperda (J.E. Smith) (Lepidoptera: Noctuidae), destaca-se como a principal espécie-praga do milho (Zea mays L.) nas regiões subtropicais e tropicais do continente americano (Juárez et al., 2012). Trata-se de uma espécie polífaga, que infesta cerca de 180 espécies de plantas hospedeiras em sua zona de distribuição e ocorrência (Casmuz et al., 2010). Por não apresentar diapausa, $S$. frugiperda é uma praga de ocorrência sazonal nas áreas de clima temperado e, sob temperaturas mais altas, pode produzir até 13 gerações por ano no milho (Afonso et al., 2009). Historicamente, a principal medida de manejo de $S$. frugiperda no Brasil tem sido o controle químico (Costa et al., 2005). Contudo, 
o comportamento larval de $S$. frugiperda, que se alimenta e se protege no cartucho das plantas de milho, limita significativamente a eficiência desse método de controle (Waquil, 2007).

Outros insetos-praga também atacam a cultura do milho no Brasil. Entre eles, têm destaque a broca-do-colmo, Diatraea saccharalis (Fabr.) (Lepidoptera: Crambidae), e a lagarta-da-espiga do milho, Helicoverpa zea (Boddy) (Lepidoptera: Noctuidae) (Farias et al., 2013). Assim como $S$. frugiperda, essas duas espécies também não são eficientemente controladas por meio da aplicação foliar de inseticidas (Cruz, 2007).

Plantas de milho geneticamente modificadas que expressam proteínas inseticidas provenientes da bactéria Bacillus thuringiensis, também conhecidas como plantas de milho $\mathrm{Bt}$, foram inicialmente aprovadas para uso comercial no Brasil em 2007. O milho MON 810 expressa a proteína inseticida Cry1A(b) e oferece níveis elevados de controle de D. saccharalis (Castro et al., 2004) e moderados de H. zea e S. frugiperda (Fernandes et al., 2003).

Os avanços na área de biotecnologia têm permitido o desenvolvimento de milhos Bt que expressam mais de uma proteína inseticida, as quais frequentemente representam modos de ação únicos e independentes (Moar \& Anilkumar, 2007). Dessa forma, caso essas premissas sejam atendidas, a piramidação de genes $B t$ pode retardar o estabelecimento de populações de insetos resistentes (Head \& Greenplate, 2012). A estratégia de piramidação de genes $B t$ é usualmente caracterizada por aumento no nível de proteção da planta Bt contra as pragas-alvo (Storer et al., 2012).

O evento MON 89034 foi desenvolvido a partir da combinação de genes que codificam as proteínas Cry1A.105 e Cry2Ab2 em um único vetor de transformação genética de plantas. Essas proteínas são ativas e eficientes para controlar lepidópteros-praga e, quando combinadas, podem retardar a evolução da resistência em populações de insetos, em condições de campo (Leite et al., 2011), e aumentar o espectro de ação da planta Bt (Manyangarirwa et al., 2006). O milho contendo o evento piramidado (MON 89034) foi aprovado para uso comercial no Brasil, pela Comissão Técnica Nacional de Biossegurança (CTNBio), em 2009.

O objetivo deste trabalho foi avaliar a eficácia do evento piramidado (MON 89034), que expressa as proteínas Cry1A.105 e Cry2Ab2, no controle dos principais lepidópteros-praga da cultura do milho no Brasil, S. frugiperda, Helicoverpa spp. e D. saccharalis.

\section{Material e Métodos}

Os experimentos foram instalados em delineamento de blocos ao acaso, com seis tratamentos e quatro repetições. As parcelas foram constituídas de cinco linhas de $10 \mathrm{~m}$, sendo as três centrais utilizadas para avaliação da produtividade e as duas laterais, para amostragem de insetos (análise destrutiva das plantas). O espaçamento foi de $0,8 \mathrm{~m}$, e foram semeadas seis sementes por metro. Foi utilizado o híbrido de milho DKB 390: convencional (não Bt); com o evento $\mathrm{Bt}$ piramidado (MON 89034), que expressa as proteínas Cry1A.105 e Cry2Ab2; e com o evento que expressa apenas a proteína Cry1A(b) (MON 810). Cada híbrido foi submetido a dois regimes de manejo: com manejo integrado de $S$. frugiperda e sem manejo integrado (testemunha). O controle foi realizado quando $20 \%$ das plantas apresentavam nota de danos $\geq 3$, pela escala de Davis et al. (1992). As parcelas experimentais foram instaladas numa área isolada do restante da gleba por duas linhas de milho convencional cultivadas como bordadura experimental.

O experimento foi conduzido no ano agrícola 2010/2011, sob infestação natural, em quatro locais:

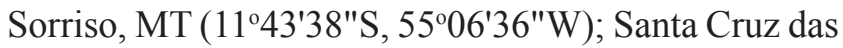

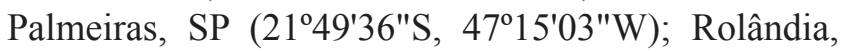
PR (231' $\left.30^{\prime \prime S}, 51^{\circ} 19^{\prime} 45^{\prime \prime W}\right)$; e Não-Me-Toque, RS $\left(28^{\circ} 05^{\prime} \mathrm{S}, 52^{\circ} 08^{\prime} \mathrm{W}\right)$. O experimento foi instalado em 29/10 e 27/12, em Santa Cruz das Palmeiras e Sorriso, respectivamente, e em 12/11, em Rolândia e Não-Me-Toque. As práticas agrícolas utilizadas foram as recomendadas para cada região. Em todos os locais, após a dessecação, foram realizadas adubações conforme o resultado da análise de solo, e o plantio foi direto manual, tendo-se utilizado dispositivo conhecido como matraca. As demais práticas culturais, como cobertura e manejo de plantas daninhas, seguiram as recomendações das boas práticas agrícolas, de acordo com as condições ambientais. Na condução do experimento, foram monitorados a incidência e os danos de $S$. frugiperda, em vários estádios de desenvolvimento (V2/3 a V10/11), e de D. saccharalis e Helicoverpa spp. no estádio R3/R4, para determinar o nível de dano para controle químico. Para a análise 
dos resultados dos danos causados por $S$. frugiperda, foram consideradas apenas as avaliações realizadas no estádio V7/8.

Em Rolândia, em razão da maior infestação de $S$. frugiperda no híbrido contendo apenas a proteína Cry1A(b), foi feita uma aplicação do inseticida espinosade (250 $\left.\mathrm{g} \mathrm{L}^{-1}\right)$, na dose de $0,1 \mathrm{~L} \mathrm{ha}^{-1}$, aos 14 dias após o plantio. Já para o manejo da praga no híbrido convencional, foram necessárias três aplicações, aos 14, 34 e 53 dias após o plantio. Em Não-Me-Toque, no híbrido contendo apenas a proteína $\mathrm{Cry} 1 \mathrm{~A}(\mathrm{~b})$, foi realizada uma aplicação do inseticida espinosade (250 $\left.\mathrm{g} \mathrm{L}^{-1}\right)$, na dose de $0,1 \mathrm{~L} \mathrm{ha}^{-1}$, aos 41 dias após o plantio, e, no híbrido convencional, foram necessárias duas aplicações, aos 31 e aos 41 dias após o plantio. A primeira aplicação foi realizada com espinosade e a segunda, com metomil (215 $\left.\mathrm{g} \mathrm{L}^{-1}\right)$, na dose de $0,4 \mathrm{~L} \mathrm{ha}^{-1}$. Todas as aplicações foram realizadas com pulverizador costal, acoplado a um cilindro de $\mathrm{CO}_{2}$ para manutenção uniforme da pressão e vazão de $200 \mathrm{~L} \mathrm{ha}^{-1}$. Nos demais locais, não foi necessária nenhuma aplicação de inseticida. Em nenhum dos locais, houve necessidade de controle químico no evento piramidado Cry1A.105 e Cry2Ab2.

Em todos os locais, os danos causados por $S$. frugiperda foram avaliados com a escala visual de sintomas de danos, que varia de zero a nove (Davis et al., 1992), em todas as plantas de uma das fileiras centrais da parcela. Foram avaliados a incidência e os danos de $S$. frugiperda, no estádio V7/8, e de D. saccharalis e de Helicoverpa spp. no estádio R3/R4. Em cada linha lateral da parcela, foram tomadas dez plantas ao acaso, para coleta e medição das lagartas sobreviventes, cujo comprimento foi classificado como: menor, igual ou maior que $1,5 \mathrm{~cm}$. Os danos causados por D. saccharalis no colmo e por S. frugiperda e Helicoverpa spp. nas espigas foram avaliados nas duas fileiras laterais, em dez plantas tomadas ao acaso, o que totalizou 20 amostras. Espigas e folhas com a bainha foram separadas dos colmos, que foram abertos ao meio, longitudinalmente, para registro das seguintes variáveis: número total de furos, e número e comprimento de cada galeria $(\mathrm{mm})$ (Farias et al., 2013). Das espigas, foi retirada a palha, e os danos causados por Helicoverpa spp. ou S. frugiperda foram avaliados com base no número e no comprimento da galeria e na área de dano nos grãos, estimada pela multiplicação do comprimento pela largura da galeria na superfície da espiga com grãos, tendo-se abandonado a ponta da espiga sem grãos (Farias et al., 2013). Essa variável indica as perdas diretas de grãos e não inclui os danos na ponta do sabugo. Para a análise estatística, foi considerado o total de galerias das 20 plantas.

A colheita das três linhas centrais foi realizada manualmente, quando os grãos atingiram cerca de $20 \%$ de umidade. Isso ocorreu, respectivamente, em 24/3, 7/4, 15/4 e 1/6 em Santa Cruz das Palmeiras, Rolândia, Não-Me-Toque e Sorriso. As espigas foram debulhadas, e os seguintes dados foram determinados: peso total de grãos por parcela $(\mathrm{kg})$, peso de mil grãos (g) e umidade dos grãos (\%). Para o efeito de análise estatística, a produção de grãos foi corrigida para $13 \%$ de umidade e para $\mathrm{kg} \mathrm{ha}^{-1}$.

A análise de variância e o teste de médias (Tukey, a $5 \%$ de probabilidade) foram realizados no programa Sisvar (Ufla, Lavras, MG). Para o efeito de análise estatística, os dados das variáveis discretas foram transformados em raiz de $\mathrm{x}+0,5$. Nas tabelas com os resultados, estão apresentadas as médias dos valores originais com a discriminação obtida a partir da análise estatística dos dados transformados. Para a análise estatística, utilizaram-se os dados originais de produção.

\section{Resultados e Discussão}

Houve diferenças significativas entre os tratamentos, em todos os locais avaliados, quanto aos danos causados por $S$. frugiperda (Tabela 1). O híbrido com o evento piramidado apresentou os menores danos em três dos quatro locais estudados. A média geral, nesse tratamento, foi próxima de um, na escala Davis, ou seja, equivalente à raspagem de folhas. Isso indica que as plantas foram infestadas, mas que não sofreram danos significativos. $O$ evento contendo apenas a proteína $\mathrm{Cry} 1 \mathrm{~A}(\mathrm{~b})$ promoveu controle intermediário em apenas dois dos quatro locais, em Santa Cruz das Palmeiras e Rolândia. Dessa forma, em determinadas condições, a tecnologia Bt, mesmo sem a estratégia de piramidação de genes, pode ser mais efetiva do que apenas o controle químico no manejo de $S$. frugiperda.

Em Santa Cruz das Palmeiras, embora relativamente baixa, a infestação de insetos foi suficiente para discriminar os tratamentos, sendo o híbrido convencional o mais danificado e o híbrido piramidado (Cry1A.105 e Cry2Ab2), o menos. 
No entanto, em Rolândia, onde houve infestação relativamente mais alta de $S$. frugiperda, observouse diferença significativa, tanto entre os tratamentos convencionais e o $\mathrm{Bt}$, quanto entre o uso de inseticida e a testemunha, nos híbridos convencional e com evento contendo apenas a proteína Cry1A(b). Nessa condição de alta infestação, houve necessidade de uma aplicação química no evento contendo apenas a proteína Cry1A(b). Ainda assim, foram detectados danos significativamente maiores no híbrido convencional (não $\mathrm{Bt}$ ) do que nos dois híbridos de milho Bt. Portanto, mesmo com o uso do controle químico, não se obteve proteção do milho convencional contra $S$. frugiperda equivalente à obtida para o milho Bt. Nesse caso, houve diferença significativa de danos no milho convencional sem aplicação de inseticida, quando comparado aos demais. Michelotto et al. (2011) verificaram redução nas notas de sintomas de dano de $S$. frugiperda de duas a três vezes, respectivamente, no milho convencional com controle químico e no milho Bt [Cry1A(b)].

$\mathrm{O}$ número médio de larvas de $S$. frugiperda pequenas $(\leq 1,5 \mathrm{~cm})$ e grandes $(>1,5 \mathrm{~cm})$ recuperadas indicou diferenças significativas entre os tratamentos nos diferentes locais (Tabela 1). Para o híbrido com o evento piramidado (Cry1A.105 e Cry2Ab2), não foram observadas lagartas, pequenas ou grandes, na maioria dos locais. Entretanto, o número de lagartas registrado foi maior no híbrido convencional, independentemente do uso ou não do controle químico, em Sorriso e Rolândia. Em geral, o número médio de lagartas, grandes ou pequenas, obtido para o híbrido

Tabela 1. Média \pm erro-padrão das notas dos danos atribuídas a Spodoptera frugiperda, em todas as plantas de duas linhas da parcela, e número de lagartas vivas em dez plantas por parcela, no estádio de desenvolvimento $\mathrm{V} 7 / \mathrm{V} 8^{(1)}$.

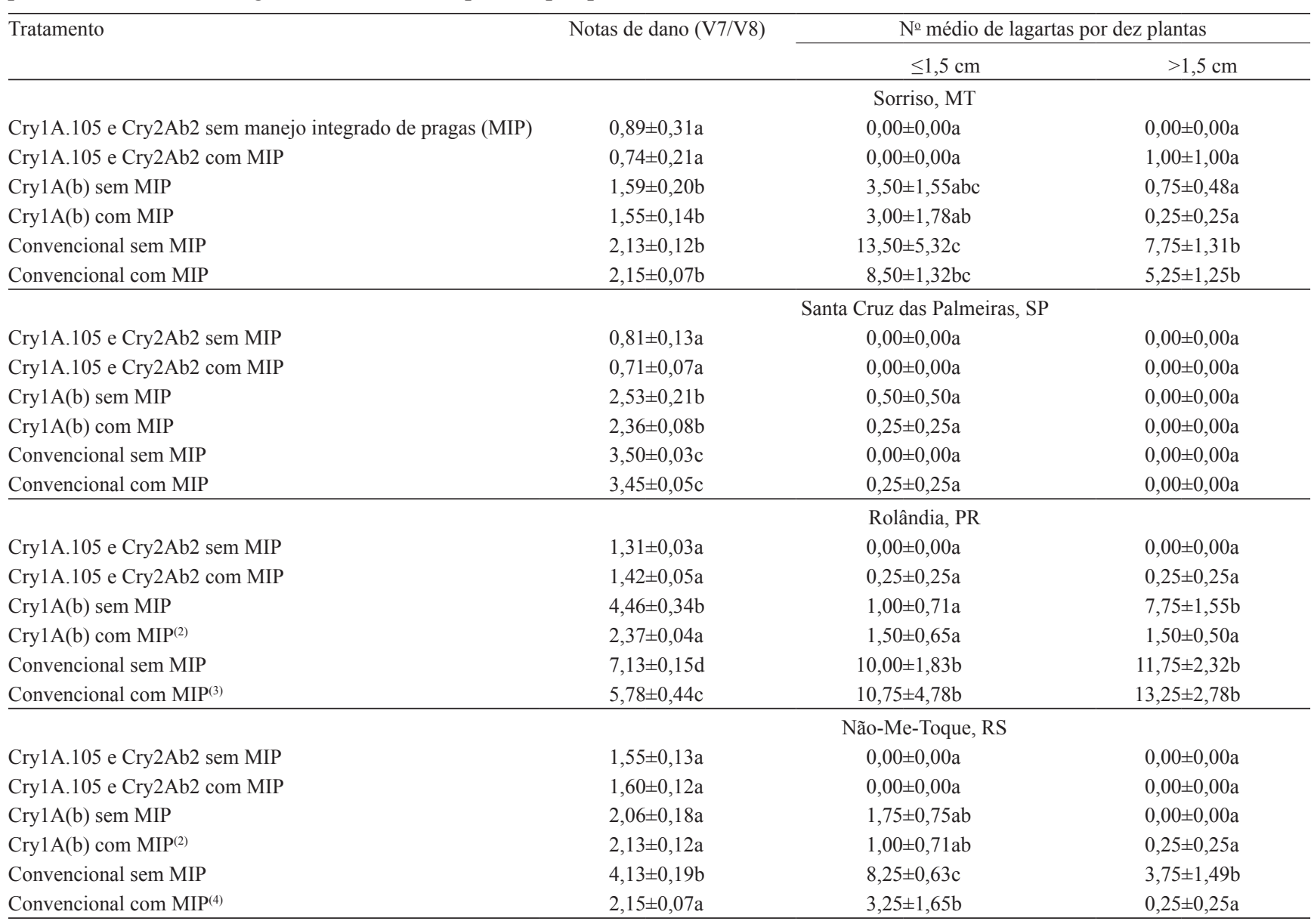

${ }^{(1)}$ Em cada local, as médias seguidas por letras iguais não diferem pelo teste de Tukey, a 5\% de probabilidade. ${ }^{(2)}$ Plantas receberam apenas uma aplicação de espinosade $\left(250 \mathrm{~g} \mathrm{~L}^{-1}\right)$, na dose de $0,1 \mathrm{~L} \mathrm{ha}^{-1}$. ${ }^{(3)}$ Plantas receberam três aplicações de espinosade $\left(250 \mathrm{~g} \mathrm{~L}^{-1}\right)$, na dose de $0,1 \mathrm{~L}^{-1}$. ${ }^{(4)}$ Plantas receberam duas aplicações de inseticidas, uma de espinosade e outra de metomil $\left(21,5 \mathrm{~g} \mathrm{~L}^{-1}\right)$, na dose de $0,4 \mathrm{~L} \mathrm{ha}^{-1}$. 
com o evento contendo apenas a proteína Cry1A(b) foi semelhante ao do híbrido com o evento piramidado, nos diferentes locais, exceto em Rolândia, onde o híbrido com o evento contendo apenas a proteína Cry1A(b) sem controle químico apresentou média significativamente maior do que os demais tratamentos com híbridos Bt. Esses resultados confirmam os obtidos por Waquil et al. (2002) de que, sob alta pressão de infestação, o evento contendo apenas a proteína Cry1A(b) promove somente a supressão de $S$. frugiperda. Isso porque, dependendo do híbrido e das condições ambientais, o monitoramento pode indicar a necessidade de controle adicional, como constatado por Michelotto et al. (2011) e Farias et al. (2013).

Em relação aos danos de D. saccharalis no estádio de desenvolvimento R3/R4, houve diferenças significativas entre os tratamentos nos diferentes locais (Tabela 2). Com base no número total de furos no colmo e no número de galerias, não houve diferença significativa entre os eventos Bt, o que mostra a eficácia do evento contendo apenas a proteína Cry1A(b) no controle dessa espécie. Entretanto, foi observada diferença significativa apenas entre os híbridos com eventos Bt e o milho convencional sem inseticida. Em Rolândia e Não-Me-Toque, onde se utilizou o controle químico para $S$. frugiperda, foi observado menor número de furos causados por $D$. saccharalis no milho convencional, semelhantemente ao verificado nos híbridos com o evento Bt.

Em Sorriso, os híbridos com os eventos $\mathrm{Bt}$ apresentaram menor número de galerias do que o

Tabela 2. Médiaterro-padrão do número total de furos e de galerias por parcela (total de 20 plantas) e do comprimento da galeria causados por Diatraea saccharalis, em milho, nos estádios de desenvolvimento R3/R4 (mm por planta) ${ }^{(1)}$.

\begin{tabular}{|c|c|c|c|}
\hline Tratamento & $\begin{array}{c}\text { Número total } \\
\text { de furos }\end{array}$ & $\begin{array}{l}\text { Número de } \\
\text { galerias }\end{array}$ & $\begin{array}{c}\text { Comprimento da galeria } \\
\text { (mm por planta) }\end{array}$ \\
\hline & \multicolumn{3}{|c|}{ Sorriso, MT } \\
\hline Cry1A.105 e Cry2Ab2 sem manejo integrado de pragas (MIP) & $0,00 \pm 0,00 \mathrm{a}$ & $0,00 \pm 0,00 \mathrm{a}$ & $0,00 \pm 0,00 \mathrm{a}$ \\
\hline Cry1A.105 e Cry2Ab2 com MIP & $0,00 \pm 0,00 \mathrm{a}$ & $0,00 \pm 0,00 \mathrm{a}$ & $0,00 \pm 0,00 \mathrm{a}$ \\
\hline CrylA(b) sem MIP & $0,50 \pm 0,50 \mathrm{a}$ & $0,25 \pm 0,25 \mathrm{ab}$ & $1,00 \pm 1,00 \mathrm{ab}$ \\
\hline Cry1A(b) com MIP & $0,00 \pm 0,00 \mathrm{a}$ & $0,00 \pm 0,00 \mathrm{a}$ & $0,00 \pm 0,00 \mathrm{a}$ \\
\hline Convencional sem MIP & $4,00 \pm 1,22 b$ & $3,75 \pm 0,95 \mathrm{c}$ & $11,50 \pm 3,78 b$ \\
\hline \multirow[t]{2}{*}{ Convencional com MIP } & $2,75 \pm 1,44 \mathrm{ab}$ & $2,50 \pm 1,19 \mathrm{bc}$ & $11,25 \pm 6,87 \mathrm{ab}$ \\
\hline & \multicolumn{3}{|c|}{ Santa Cruz das Palmeiras, SP } \\
\hline Cry1A.105 e Cry2Ab2 sem MIP & $0,00 \pm 0,00 \mathrm{a}$ & $0,00 \pm 0,00 \mathrm{a}$ & $0,00 \pm 0,00 \mathrm{a}$ \\
\hline Cry1A.105 e Cry2Ab2 com MIP & $0,00 \pm 0,00 \mathrm{a}$ & $0,00 \pm 0,00 \mathrm{a}$ & $0,00 \pm 0,00 \mathrm{a}$ \\
\hline Cry1A(b) sem MIP & $0,00 \pm 0,00 \mathrm{a}$ & $0,00 \pm 0,00 \mathrm{a}$ & $0,00 \pm 0,00 \mathrm{a}$ \\
\hline Cry1A(b) com MIP & $0,00 \pm 0,00 \mathrm{a}$ & $0,00 \pm 0,00 \mathrm{a}$ & $0,00 \pm 0,00 \mathrm{a}$ \\
\hline Convencional sem MIP & $5,25 \pm 3,09 \mathrm{a}$ & $2,75 \pm 1,38 \mathrm{a}$ & $15,81 \pm 7,35 b$ \\
\hline \multirow[t]{2}{*}{ Convencional com MIP } & $12,00 \pm 2,42 b$ & $6,50 \pm 1,55 b$ & $45,13 \pm 12,57 \mathrm{c}$ \\
\hline & \multicolumn{3}{|c|}{ Rolândia, PR } \\
\hline Cry1A.105 e Cry2Ab2 sem MIP & $0,75 \pm 0,75 \mathrm{a}$ & $0,00 \pm 0,00 \mathrm{a}$ & $0,00 \pm 0,00 \mathrm{a}$ \\
\hline Cry1A.105 e Cry2Ab2 com MIP & $0,00 \pm 0,00 \mathrm{a}$ & $0,00 \pm 0,00 \mathrm{a}$ & $0,00 \pm 0,00 \mathrm{a}$ \\
\hline Cry1A(b) sem MIP & $5,50 \pm 1,76 \mathrm{ab}$ & $0,75 \pm 0,48 \mathrm{a}$ & $0,80 \pm 0,44 \mathrm{a}$ \\
\hline Cry1A(b) com MIP ${ }^{(2)}$ & $4,25 \pm 3,33 \mathrm{ab}$ & $0,00 \pm 0,00 \mathrm{a}$ & $0,00 \pm 0,00 \mathrm{a}$ \\
\hline Convencional sem MIP & $68,75 \pm 15,52 \mathrm{c}$ & $11,75 \pm 1,31 b$ & $33,83 \pm 8,64 b$ \\
\hline \multirow[t]{2}{*}{ Convencional com $\mathrm{MIP}^{(3)}$} & $16,00 \pm 6,34 \mathrm{~b}$ & $6,00 \pm 5,02 \mathrm{ab}$ & $18,64 \pm 14,26 \mathrm{ab}$ \\
\hline & \multicolumn{3}{|c|}{ Não-Me-Toque, RS } \\
\hline Cry1A.105 e Cry2Ab2 sem MIP & $0,00 \pm 0,00 \mathrm{a}$ & $0,00 \pm 0,00 \mathrm{a}$ & $0,00 \pm 0,00 \mathrm{a}$ \\
\hline Cry1A.105 e Cry2Ab2 com MIP & $0,00 \pm 0,00 \mathrm{a}$ & $0,00 \pm 0,00 \mathrm{a}$ & $0,00 \pm 0,00 \mathrm{a}$ \\
\hline Cry1A(b) sem MIP & $0,00 \pm 0,00 \mathrm{a}$ & $0,00 \pm 0,00 \mathrm{a}$ & $0,00 \pm 0,00 \mathrm{a}$ \\
\hline Cry1A(b) com MIP(2) & $0,75 \pm 0,48 \mathrm{ab}$ & $0,75 \pm 0,48 \mathrm{a}$ & $2,13 \pm 1,66 a$ \\
\hline Convencional sem MIP & $4,25 \pm 1,75 b$ & $2,75 \pm 1,80 \mathrm{a}$ & $6,75 \pm 5,36 \mathrm{a}$ \\
\hline Convencional com MIP(4) & $0,50 \pm 0,29 \mathrm{a}$ & $0,25 \pm 0,25 \mathrm{a}$ & $3,25 \pm 1,97 \mathrm{a}$ \\
\hline
\end{tabular}

${ }^{(1)}$ Em cada local, as médias seguidas por letras iguais não diferem pelo teste de Tukey, a 5\% de probabilidade. (2)Plantas receberam apenas uma aplicação de espinosade $\left(250 \mathrm{~g} \mathrm{~L}^{-1}\right)$, na dose de $0,1 \mathrm{~L} \mathrm{ha}^{-1}$. ${ }^{(3)}$ Plantas receberam três aplicações de espinosade $\left(250 \mathrm{~g} \mathrm{~L}^{-1}\right)$, na dose de $0,1 \mathrm{~L}^{-1}{ }^{-1}{ }^{(4)} \mathrm{Plantas}$ receberam duas aplicações de inseticidas, uma de espinosade e outra de metomil $\left(21,5 \mathrm{~g} \mathrm{~L}^{-1}\right)$, na dose de $0,4 \mathrm{~L} \mathrm{ha}^{-1}$. 
híbrido convencional. Já em Rolândia, o híbrido convencional que recebeu controle químico para S. frugiperda não diferiu dos híbridos Bt. Apesar de, no Brasil, não se utilizar o controle químico para D. saccharalis no milho, nos Estados Unidos, a pulverização durante o período de desenvolvimento da planta reduz a infestação e os seus danos (Bessin et al., 1990). Em Rolândia, onde se verificou a infestação mais alta de $D$. saccharalis, a mesma tendência foi observada, e o comprimento da galeria foi menor nos híbridos transgênicos e maior no convencional sem o controle químico para $S$. frugiperda. A eficiência dos eventos Bt no controle de D. saccharalis também foi recentemente relatada por Michelotto et al. (2011), ao analisar o híbrido DKB 390. Okumura et al. (2013), ao avaliar o evento piramidado (Cry1A.105 e Cry2Ab2) e o controle químico para $D$. saccharalis, observaram 97,1 e 74,6\% de eficiência, respectivamente. Contudo, Farias et al. (2013) não constataram efeito algum da aplicação de inseticida sobre $D$. saccharalis.

No ensaio conduzido em Santa Cruz das Palmeiras, em razão da baixa infestação, nenhuma diferença significativa foi observada entre os tratamentos, com base nas variáveis utilizadas para estimar os danos das larvas de Helicoverpa spp. e $S$. frugiperda na espiga (Tabela 3). Por sua vez, em Sorriso e Rolândia, houve diferenças entre os tratamentos com híbridos transgênicos e convencionais, no número e no comprimento de galerias. Em Não-Me-Toque, apenas as variáveis comprimento da galeria e área de danos

Tabela 3. Média \pm erro-padrão do número de galerias (total de 20 plantas), do comprimento da galeria (mm por planta) e da área de danos nos grãos ( $\mathrm{mm}^{2}$ por planta) causados por Helicoverpa spp. ou Spodoptera frugiperda, no estádio de desenvolvimento reprodutivo $\mathrm{R} 3 / \mathrm{R} 4^{(1)}$.

\begin{tabular}{|c|c|c|c|}
\hline Tratamento & $\begin{array}{l}\text { Número de } \\
\text { galerias }\end{array}$ & $\begin{array}{l}\text { Comprimento da galeria } \\
\text { (mm por planta) }\end{array}$ & $\begin{array}{c}\text { Área de dano } \\
\left(\mathrm{mm}^{2} \text { por planta }\right)\end{array}$ \\
\hline & \multicolumn{3}{|c|}{ Sorriso, MT } \\
\hline Cry1A.105 e Cry2Ab2 sem manejo integrado de pragas (MIP) & $0,00 \pm 0,00 \mathrm{a}$ & $0,00 \pm 0,00 \mathrm{a}$ & $0,00 \pm 0,00 \mathrm{a}$ \\
\hline Cry1A.105 e Cry2Ab2 com MIP & $0,00 \pm 0,00 \mathrm{a}$ & $0,00 \pm 0,00 \mathrm{a}$ & $0,00 \pm 0,00 \mathrm{a}$ \\
\hline Cry1A(b) sem MIP & $0,25 \pm 0,25 \mathrm{a}$ & $0,25 \pm 0,25 \mathrm{a}$ & $0,00 \pm 0,00 \mathrm{a}$ \\
\hline Cry1A(b) com MIP & $0,00 \pm 0,00 \mathrm{a}$ & $0,00 \pm 0,00 \mathrm{a}$ & $0,00 \pm 0,00 \mathrm{a}$ \\
\hline Convencional sem MIP & $3,00 \pm 1,73 \mathrm{ab}$ & $4,31 \pm 1,74 \mathrm{~b}$ & $0,00 \pm 0,00 \mathrm{a}$ \\
\hline \multirow[t]{2}{*}{ Convencional com MIP } & $4,50 \pm 1,32 \mathrm{~b}$ & $4,88 \pm 1,65 \mathrm{~b}$ & $0,00 \pm 0,00 \mathrm{a}$ \\
\hline & \multicolumn{3}{|c|}{ Santa Cruz das Palmeiras, SP } \\
\hline Cry1A.105 e Cry2Ab2 sem MIP & $0,00 \pm 0,00 \mathrm{a}$ & $0,00 \pm 0,00 \mathrm{a}$ & $0,00 \pm 0,00 \mathrm{a}$ \\
\hline Cry1A.105 e Cry2Ab2 com MIP & $0,00 \pm 0,00 \mathrm{a}$ & $0,00 \pm 0,00 \mathrm{a}$ & $0,00 \pm 0,00 \mathrm{a}$ \\
\hline Cry1A(b) sem MIP & $0,00 \pm 0,00 \mathrm{a}$ & $0,00 \pm 0,00 \mathrm{a}$ & $0,00 \pm 0,00 \mathrm{a}$ \\
\hline Cry1A(b) com MIP & $0,00 \pm 0,00 \mathrm{a}$ & $0,00 \pm 0,00 \mathrm{a}$ & $0,00 \pm 0,00 \mathrm{a}$ \\
\hline Convencional sem MIP & $0,25 \pm 0,25 \mathrm{a}$ & $0,13 \pm 0,13 \mathrm{a}$ & $0,09 \pm 0,09 \mathrm{a}$ \\
\hline \multirow[t]{2}{*}{ Convencional com MIP } & $0,00 \pm 0,00 \mathrm{a}$ & $0,00 \pm 0,00 \mathrm{a}$ & $0,00 \pm 0,00 \mathrm{a}$ \\
\hline & \multicolumn{3}{|c|}{ Rolândia, PR } \\
\hline Cry1A.105 e Cry2Ab2 sem MIP & $0,00 \pm 0,00 \mathrm{a}$ & $0,00 \pm 0,00 \mathrm{a}$ & $0,00 \pm 0,00 \mathrm{a}$ \\
\hline Cry1A.105 e Cry2Ab2 com MIP & $0,50 \pm 0,29 \mathrm{ab}$ & $0,38 \pm 0,38 \mathrm{ab}$ & $0,15 \pm 0,15 \mathrm{a}$ \\
\hline Cry1A(b) sem MIP & $0,75 \pm 0,25 \mathrm{ab}$ & $0,63 \pm 0,38 \mathrm{ab}$ & $0,10 \pm 0,10 \mathrm{a}$ \\
\hline Cry1A(b) com MIP(2) & $0,25 \pm 0,25 \mathrm{ab}$ & $0,19 \pm 0,19 \mathrm{ab}$ & $0,08 \pm 0,08 \mathrm{a}$ \\
\hline Convencional sem MIP & $3,25 \pm 1,31 \mathrm{bc}$ & $5,31 \pm 2,58 \mathrm{bc}$ & $2,13 \pm 1,03 \mathrm{ab}$ \\
\hline \multirow[t]{2}{*}{ Convencional com MIP ${ }^{(3)}$} & $5,50 \pm 1,85 \mathrm{c}$ & $8,69 \pm 3,03 \mathrm{c}$ & $3,48 \pm 1,21 \mathrm{~b}$ \\
\hline & \multicolumn{3}{|c|}{ Não-Me-Toque, RS } \\
\hline Cry1A.105 e Cry2Ab2 sem MIP & $2,25 \pm 0,85 \mathrm{abc}$ & $1,40 \pm 0,54 \mathrm{a}$ & $0,78 \pm 0,32 \mathrm{a}$ \\
\hline Cry1A.105 e Cry2Ab2 com MIP & $0,25 \pm 0,25 \mathrm{a}$ & $0,13 \pm 0,13 \mathrm{a}$ & $0,32 \pm 0,34 \mathrm{a}$ \\
\hline Cry1A(b) sem MIP & $1,00 \pm 0,58 \mathrm{ab}$ & $1,00 \pm 0,42 \mathrm{a}$ & $1,32 \pm 0,82 \mathrm{ab}$ \\
\hline Cry1A(b) com $\mathrm{MIP}^{(2)}$ & $1,75 \pm 0,63 \mathrm{abc}$ & $1,00 \pm 0,38 \mathrm{a}$ & $0,91 \pm 0,34 \mathrm{ab}$ \\
\hline Convencional sem MIP & $5,75 \pm 2,69 \mathrm{bc}$ & $3,83 \pm 1,17 \mathrm{~b}$ & $5,00 \pm 1,62 \mathrm{c}$ \\
\hline Convencional com MIP(4) & $7,00 \pm 0,58 \mathrm{c}$ & $4,07 \pm 0,21 \mathrm{~b}$ & $3,94 \pm 0,19 \mathrm{bc}$ \\
\hline
\end{tabular}

${ }^{(1)}$ Em cada local, as médias seguidas por letras iguais não diferem pelo teste de Tukey, a 5\% de probabilidade. (2)Plantas receberam apenas uma aplicação de espinosade $\left(250 \mathrm{~g} \mathrm{~L}^{-1}\right)$, na dose de $0,1 \mathrm{~L} \mathrm{ha}^{-1}$. ${ }^{(3)}$ Plantas receberam três aplicações de espinosade $\left(250 \mathrm{~g} \mathrm{~L}^{-1}\right)$, na dose de $0,1 \mathrm{~L}^{-1}{ }^{-1}$. ${ }^{(4)} \mathrm{Plantas}$ receberam duas aplicações de inseticidas, uma de espinosade e outra de metomil $\left(21,5 \mathrm{~g} \mathrm{~L}^{-1}\right)$, na dose de $0,4 \mathrm{~L} \mathrm{ha}^{-1}$. 
apresentaram diferenças entre os híbridos transgênicos e convencional. Em Rolândia e Não-Me-Toque, o controle químico para $S$. frugiperda não promoveu redução de danos nas espigas, tanto no híbrido $\mathrm{Bt}$ com o evento contendo apenas a proteína Cry1A(b), quanto no híbrido convencional. Esses resultados estão de acordo com os de Farias et al. (2013), que não detectaram efeito da aplicação de inseticidas na incidência de $H$. zea, mas verificaram redução da incidência e dos danos dessa praga-alvo no milho que expressa a proteína Cry1A(b).

Segundo Michelotto et al. (2011), a infestação da ponta da espiga do milho foi reduzida de $68 \%$, no milho convencional, para apenas $21 \%$ no híbrido Cry1A(b). No presente trabalho, em Rolândia, Não-Me-Toque e Sorriso, constatou-se que as tecnologias Bt testadas contribuíram para o manejo de Helicoverpa spp. e de $S$. frugiperda na espiga, sítio de difícil controle das lagartas por inseticidas químicos. Resultados semelhantes também foram reportados por Farias et al. (2013).

Em relação à produção de grãos, houve diferenças significativas para rendimento em três dos quatro locais avaliados, e, para peso de mil grãos, apenas em Não-Me-Toque (Tabela 4). Foram observadas diferenças somente entre os tratamentos com o híbrido com o evento piramidado e com o híbrido convencional sem controle químico de $S$. frugiperda. Em Santa Cruz das Palmeiras, não houve diferença significativa entre os tratamentos para as variáveis analisadas, em razão da baixa infestação pelas pragas-alvo na área em que o experimento foi conduzido. Nos demais locais,

Tabela 4. Média \pm erro-padrão do peso de mil grãos e do rendimento de grãos corrigidos para $13 \%$ de umidade ${ }^{(1)}$, no ano agrícola 2010/2011.

\begin{tabular}{|c|c|c|}
\hline Tratamento & $\begin{array}{l}\text { Peso de mil } \\
\text { grãos }(\mathrm{g})\end{array}$ & $\begin{array}{l}\text { Rendimento de } \\
\text { grãos }\left(\mathrm{kg} \mathrm{ha}^{-1}\right)\end{array}$ \\
\hline & \multicolumn{2}{|c|}{ Sorriso, MT } \\
\hline Cry1A.105 e Cry2Ab2 sem manejo integrado de pragas (MIP) & $344,38 \pm 8,59 a$ & $10.002 \pm 200 \mathrm{ab}$ \\
\hline Cry1A.105 e Cry2Ab2 com MIP & $356,14 \pm 3,38 \mathrm{a}$ & $10.104 \pm 210 \mathrm{a}$ \\
\hline Cry1A(b) sem MIP & $339,03 \pm 2,57 \mathrm{a}$ & $9.739 \pm 224 \mathrm{ab}$ \\
\hline Cry1A(b) com MIP & $341,69 \pm 2,93 a$ & $9.474 \pm 206 \mathrm{bc}$ \\
\hline Convencional sem $\mathrm{MIP}^{(2)}$ & $351,66 \pm 3,04 \mathrm{a}$ & $8.769 \pm 73 d$ \\
\hline \multirow[t]{2}{*}{ Convencional com MIP } & $352,60 \pm 0,27 \mathrm{a}$ & $9.137 \pm 207 \mathrm{~cd}$ \\
\hline & \multicolumn{2}{|c|}{ Santa Cruz das Palmeiras, SP } \\
\hline Cry1A.105 e Cry2Ab2 sem MIP & $236,68 \pm 10,53 a$ & $14.041 \pm 392 \mathrm{a}$ \\
\hline Cry1A.105 e Cry2Ab2 com MIP & $261,46 \pm 33,45 \mathrm{a}$ & $13.972 \pm 450 \mathrm{a}$ \\
\hline Cry1A(b) sem MIP & $214,95 \pm 13,27 \mathrm{a}$ & $13.978 \pm 398 \mathrm{a}$ \\
\hline Cry1A(b) com MIP & $212,48 \pm 15,72 a$ & $14.250 \pm 310 \mathrm{a}$ \\
\hline Convencional sem MIP & $253,60 \pm 13,68 \mathrm{a}$ & $14.124 \pm 324 \mathrm{a}$ \\
\hline \multirow[t]{2}{*}{ Convencional com MIP } & $263,63 \pm 18,86 \mathrm{a}$ & $13.691 \pm 353 \mathrm{a}$ \\
\hline & \multicolumn{2}{|c|}{ Rolândia, PR } \\
\hline Cry1A.105 e Cry2Ab2 sem MIP & $476,37 \pm 2,54 a$ & $14.235 \pm 305 \mathrm{a}$ \\
\hline Cry1A.105 e Cry2Ab2 com MIP & $484,59 \pm 1,04 \mathrm{a}$ & $14.064 \pm 418 \mathrm{ab}$ \\
\hline Cry1A(b) sem MIP & $473,79 \pm 2,52 \mathrm{a}$ & $14.372 \pm 198 \mathrm{a}$ \\
\hline Cry1A(b) com MIP(2) & $475,33 \pm 8,01 \mathrm{a}$ & $13.798 \pm 503 \mathrm{ab}$ \\
\hline Convencional sem MIP & $465,42 \pm 2,08 \mathrm{a}$ & $10.125 \pm 736 \mathrm{c}$ \\
\hline \multirow[t]{2}{*}{ Convencional com $\mathrm{MIP}^{(3)}$} & $474,05 \pm 2,94 \mathrm{a}$ & $12.040 \pm 458 \mathrm{bc}$ \\
\hline & \multicolumn{2}{|c|}{ Não-Me-Toque, RS } \\
\hline Cry1A.105 e Cry2Ab2 sem MIP & $356,70 \pm 7,89 \mathrm{ab}$ & $14.034 \pm 208 \mathrm{a}$ \\
\hline Cry1A.105 e Cry2Ab2 com MIP & $351,35 \pm 5,07 \mathrm{a}$ & $14.050 \pm 238 \mathrm{a}$ \\
\hline Cry1A(b) sem MIP & $376,04 \pm 3,94 \mathrm{ab}$ & $14.453 \pm 281 \mathrm{a}$ \\
\hline Cry1A(b) com MIP(2) & $366,40 \pm 6,50 \mathrm{ab}$ & $14.142 \pm 359 \mathrm{a}$ \\
\hline Convencional sem MIP & $385,44 \pm 8,21 \mathrm{~b}$ & $12.732 \pm 306 b$ \\
\hline Convencional com MIP ${ }^{(4)}$ & $357,49 \pm 6,10 \mathrm{ab}$ & $13.402 \pm 415 \mathrm{ab}$ \\
\hline
\end{tabular}

${ }^{(1)} \mathrm{Em}$ cada local, as médias seguidas por letras iguais não diferem pelo teste de Tukey, a 5\% de probabilidade. (2)Plantas receberam apenas uma aplicação de espinosade $\left(250 \mathrm{~g} \mathrm{~L}^{-1}\right)$, na dose de $0,1 \mathrm{~L} \mathrm{ha}^{-1}$. ${ }^{(3)}$ Plantas receberam três aplicações de espinosade $\left(250 \mathrm{~g} \mathrm{~L}^{-1}\right)$, na dose de $0,1 \mathrm{~L}^{-1}{ }^{-1}$. ${ }^{(4)} \mathrm{Plantas}$ receberam duas aplicações de inseticidas, uma de espinosade e outra de metomil $\left(21,5 \mathrm{~g} \mathrm{~L}^{-1}\right)$, na dose de $0,4 \mathrm{~L} \mathrm{ha}^{-1}$. 
os híbridos $\mathrm{Bt}$ produziram significativamente mais que o híbrido convencional sem controle químico. Em Sorriso, embora a infestação de $S$. frugiperda não tenha atingido o nível de controle, os híbridos Bt diferiram significativamente do convencional sem controle químico, quanto ao rendimento de grãos. Isso indica que, mesmo níveis de danos visuais abaixo do nível de controle para $S$. frugiperda, podem reduzir significativamente a produtividade. Lourenção \& Fernandes (2013) obtiveram resultados semelhantes em seis municípios, em Mato Grosso do Sul, ao integrar milho Bt [Cry1A(b) e Cry1F] e controle químico, para redução dos danos foliares causados por S. frugiperda e produtividade. É importante ressaltar que a produtividade depende de fatores ligados à planta e de suas interações com as condições edafoclimáticas, o que faz com que varie sensivelmente de um local para outro. Nesse experimento, foram obtidas produtividades médias que variaram de 8,8 a 14,5 $\mathrm{Mg} \mathrm{ha}^{-1}$. Esse dado evidencia os efeitos da variação do nível de infestação das pragas e das interações edafoclimáticas na produtividade.

A piramidação de genes $B t$ é uma estratégia eficaz no manejo de pragas. Caso sejam atendidas as premissas da piramidação, a frequência de alelos de resistência a duas (ou mais) proteínas Bt na população dos insetos alvo é relativamente menor do que na presença de um evento com apenas uma proteína Bt. Assim, a quantidade de insetos suscetíveis necessária para diluir os alelos de resistência é menor, o que viabiliza a redução da área de refúgio (Siebert et al., 2012). Mesmo ao se utilizar eventos piramidados, é essencial o monitoramento das populações nas lavouras, e, caso seja atingido o nível de ação, deve-se utilizar outros métodos de controle. Cabe reiterar que o Manejo Integrado de Pragas em campo com milho Bt inclui o plantio de área de refúgio para preservar a eficácia das tecnologias (Manyangarirwa et al., 2006).

\section{Conclusões}

1. O híbrido de milho DKB 390 transgênico, com o evento piramidado que expressa as proteínas Cry1A.105 e Cry2Ab2, confere proteção contra Spodoptera frugiperda e Diatraea saccharalis, e dispensa o controle químico, quando comparado ao híbrido de milho DKB 390 convencional.

2. O milho híbrido Bt que expressa apenas a proteína Cry1A(b) reduz os danos causados por S. frugiperda, mas demanda monitoramento para tomada de decisão sobre o uso de controle químico.

3. Diatraea saccharalis é controlada eficientemente tanto pelo híbrido com evento piramidado quanto pelo híbrido Cry1A(b), que apresentam rendimento maior que o híbrido convencional.

4. Os híbridos transgênicos apresentam menores danos à espiga causados por Helicoverpa spp. ou $S$. frugiperda que o convencional.

\section{Referências}

AFONSO, A.P.S.; WREGE, M.; MARTINS, J.F. da S.; NAVA, D.E. Simulação do zoneamento ecológico da lagarta-do-cartucho no Rio Grande do Sul com o aumento de temperatura. Arquivos do Instituto Biológico, v.76, p.607-612, 2009.

BESSIN, R.T.; MOSER, E.B.; REAGAN, T.E. Integration of control tactics for management of the sugarcane borer (Lepidoptera: Pyralidae) in Louisiana sugarcane. Journal of Economic Entomology, v.83, p.1563-1569, 1990.

CASMUZ, A.; JUÁREZ, M.L.; SOCÍAS, M.G.; MURÚA, M.G.; PRIETO, S.; MEDINA, S.; WILLINK, E.; GASTAMINZA, G. Revisión de los hospederos del gusano cogollero del maíz, Spodoptera frugiperda (Lepidoptera: Noctuidae). Revista de la Sociedad Entomológica Argentina, v.69, p.209-231, 2010.

CASTRO, B.A.; LEONARD, B.R.; RILEY, T.J. Management of feeding damage and survival of southwestern corn borer and sugarcane borer (Lepidoptera: Crambidae) with Bacillus thuringiensis transgenic field corn. Journal of Economic Entomology, v.97, p.2106-2116, 2004. DOI: 10.1603/0022-0493-97.6.2106.

COSTA, M.A.G.; GRÜTZMACHER, A.D.; MARTINS, J.F. da S.; COSTA, E.C.; STORCH, G.; STEFANELLO JÚNIOR, G.J. Eficácia de diferentes inseticidas e de volumes de calda no controle de Spodoptera frugiperda nas culturas do milho e sorgo cultivados em várzea. Ciência Rural, v.35, p.1234-1242, 2005. DOI: 10.1590/ S0103-84782005000600002.

CRUZ, I. A broca da cana-de-açúcar, Diatraea saccharalis, em milho, no Brasil. Sete Lagoas: Embrapa Milho e Sorgo, 2007. 12p. (Embrapa Milho e Sorgo. Circular técnica, 90).

DAVIS, F.M.; NG, S.S.; WILLIAMS, W.P. Visual rating scales for screening whorl-stage corn for resistance to fall armyworm. Mississippi State: Mississippi State University, 1992. 9p. (Technical bulletin, 186).

FARIAS, J.R.; COSTA, E.C.; GUEDES, J.V.C.; ARBAGE, A.P.; B. NETO, A.; BIGOLIN, M.; PINTO, F.F. Managing the sugarcane borer, Diatraea saccharalis, and corn earworm, Helicoverpa $z e a$, using $B t$ corn and insecticide treatments. Journal of Insect Science, v.13, p.1-10, 2013.

FERNANDES, O.D.; PARRA, J.R.P.; F. NETO, A.; PÍCOLI, R.; BORGATTO, A.F.; DEMÉTRIO, C.G.B. Efeito do milho geneticamente modificado MON 810 sobre a lagarta-do-cartucho Spodoptera frugiperda (J.E. Smith, 1797) 
(Lepidoptera:Noctuidae). Revista Brasileira de Milho e Sorgo, v.2, p.25-35, 2003.

HEAD, G.P.; GREENPLATE, J. The design and implementation of insect resistance management programs for Bt Crops. GM Crops and Food: Biotechnology in Agriculture and the Food Chain, v.3, p.144-153, 2012. DOI: 10.4161/gmcr.20743.

JUÁREZ, M.L.; MURÚA, M.G.; GARCÍA, M.G.; ONTIVERO, M.; VERA, M.T.; VILARDI, J.C.; GROOT, A.T.; CASTAGNARO, A.P.; GASTAMINZA, G.; WILLINK, E. Host association of Spodoptera frugiperda (Lepidoptera: Noctuidae) corn and rice strains in Argentina, Brazil, and Paraguay. Journal of Economic Entomology, v.105, p.573-582, 2012. DOI: $10.1603 / \mathrm{EC} 11184$.

LEITE, N.A.; MENDES, S.M.; WAQUIL, J.M.; PEREIRA, E.J.G. O milho Bt no Brasil: a situação e a evolução da resistência de insetos. Sete Lagoas: Embrapa Milho e Sorgo, 2011. 46p. (Embrapa Milho e Sorgo. Documentos, 133).

LOURENÇÃO, A.L.F.; FERNANDES, M.G. Avaliação do milho Bt Cry1A(b) e Cry1F no controle de Spodoptera frugiperda (J. E. Smith, 1797) (Lepidoptera: Noctuidae) em condições de campo. Científica, v.41, p.164-188, 2013.

MANYANGARIRWA, W.; TURNBULL, M.; MCCUTCHEON, G.S.; SMITH, J.P. Gene pyramiding as a $B t$ resistance management strategy: how sustainable is this strategy? African Journal of Biotechnology, v.5, p.781-785, 2006.

MICHELOTTO, M.D.; FINOTO, E.L.; MARTINS, A.L.M.; DUARTE, A.P. Interação entre transgênicos $(B t)$ e inseticidas no controle de pragas-chave em híbridos de milho-safrinha. Arquivos do Instituto Biológico, v.78, p.71-79, 2011.
MOAR, W.J.; ANILKUMAR, K.J. The power of pyramid. Science, v.318, p.1561-1562, 2007. DOI: 10.1126/science.1151313.

OKUMURA, R.S.; MARIANO, D. de C.; DALLACORT, R.; ZORZENONI, T.O.; ZACCHEO, P.V.C.; OLIVEIRA NETO, C.F. de; CONCEICAO, H.E.O. da; LOBATO, A.K. da S. Agronomic efficiency of Bacillus thuringiensis (Bt) maize hybrids in pests control on Lucas do Rio Verde city, State of Mato Grosso, Brazil. African Journal of Agricultural Research, v.8, p.2232-2239, 2013. DOI: 10.5897/AJAR12.2201.

SIEBERT, M.W; NOLTING, S.P.; HENDRIX, W.; DHAVALA, S.; CRAIG, C.; LEONARD, B.R.; STEWART, S.D.; ALL, J.; MUSSER, F.R.; BUNTIN, G.D.; SAMUEL, L. Evaluation of corn hybrids expressing Cry1F, Cry1A.105, Cry2Ab2, Cry34Ab1/ Cry35Ab1, and Cry3Bb1 against southern United States insect pests. Journal of Economic Entomology, v.105, p.1825-1834, 2012. DOI: $10.1603 / \mathrm{EC} 12155$.

STORER, N.P.; THOMPSON, G.D.; HEAD, G.P. Application of pyramided traits against Lepidoptera in insect resistance management for $B t$ crops. GM Crops and Food: Biotechnology in Agriculture and the Food Chain, v.3, p.154-162, 2012. DOI: 10.4161/gmcr.20945.

WAQUIL, J.M. Manejo fitossanitário e ambiental: milho transgênico $B t$ e resistência das plantas ao ataque da lagarta-do-cartucho. 2007. Disponível em: $<$ http://www. infobibos. com/Artigos/2007_1/manfito/index.htm>. Acesso em: 7 fev. 2014.

WAQUIL, J.M.; VILELLA, F.M.F.; FOSTER, J.E. Resistência de milho (Zea mays L.) transgênico à lagarta-do-cartucho, Spodoptera frugiperda (Smith) (Lepidoptera: Noctuidae). Revista Brasileira de Milho e Sorgo, v.1, p.1-11, 2002.

Recebido em 4 de agosto de 2013 e aprovado em 28 de novembro de 2013

Pesq. agropec. bras., Brasília, v.48, n.12, p.1529-1537, dez. 2013 DOI: 10.1590/S0100-204X2013001200001 